\title{
Erratum to: A Small Chip Area Stochastic Calibration for TDC Using Ring Oscillator
}

\author{
Kentaroh Katoh • Yutaro Kobayashi • Takeshi Chujo • \\ Junshan Wang • Ensi Li • Congbing Li • \\ Haruo Kobayashi
}

Published online: 23 December 2014

(C) Springer Science+Business Media New York 2014

\section{Erratum to: J Electron Test (2014) 30(6):653-663 \\ DOI 10.1007/s10836-014-5486-0}

The original version of this article unfortunately contained the following mistakes.

1. Below the title and in biography, an author's name Congbing $\mathrm{Li}$ is spelled incorrectly.

2. In the biography of Kentaroh Katoh,

Since 2011, he has been a member of Tsuruoka National College of Technology. -> Since 2011, he has been a member of National Institute of Technology, Tsuruoka College.

$\mathrm{He}$ is currently a research staff of Gunma University, too. $\rightarrow \mathrm{He}$ was a visiting researcher of Gunma University in 2013.

The online version of the original article can be found at http://dx.doi.org/ 10.1007/s10836-014-5486-0.

\footnotetext{
K. Katoh $(\bowtie)$

National Institute of Technology, Tsuruoka College, Tsuruoka,

Yamagata, 997-8511, Japan

e-mail: k-katoh@tsuruoka-nct.ac.jp

Y. Kobayashi $\cdot$ T. Chujo $\cdot$ J. Wang $\cdot$ E. Li $\cdot$ C. Li $\cdot$ H. Kobayashi

Division of Electronics and Informatics, Faculty of Science and

Technology, Gunma University, 1-5-1 Tenjin-cho, Kiryu,

Gunma, 376-8515, Japan

Y. Kobayashi

e-mail: t10306028@gunma-u.ac.jp

T. Chujo

e-mail: t10306054@gunma-u.ac.jp

J. Wang

e-mail: t10306902@gunma-u.ac.jp

E. Li

e-mail: t13801499@gunma-u.ac.jp

C. Li

e-mail: t13802483@gunma-u.ac.jp

H. Kobayashi

e-mail: k_haruo@el.gunma-u.ac.jp
} 